\title{
Ground vibrations and airborne sounds generated by motion of rock in a river bed
}

\author{
C.-J. Huang ${ }^{1}$, C.-H. Yeh ${ }^{2}$, C.-Y. Chen ${ }^{1}$, and S.-T. Chang ${ }^{1}$ \\ ${ }^{1}$ Department of Hydraulic and Ocean Engineering, National Cheng Kung University, Tainan, Taiwan \\ ${ }^{2}$ Monitoring and Management Division, Soil and Water Conservation Bureau, Council of Agriculture, Nantou, Taiwan
}

Received: 16 January 2008 - Revised: 8 August 2008 - Accepted: 30 August 2008 - Published: 21 October 2008

\begin{abstract}
This study investigates how ground vibrations (underground sounds) and airborne sounds that are produced by rocks in a river bed differ from each other. Airborne and underground sounds were simultaneously received at three microphones and three geophones, respectively. These sound signals were then analyzed using both the Fast Fourier Transform and the Gabor Transform to represent them in both the frequency and time-frequency domains. Experimental data indicate that the frequency of both airborne and underground sounds produced by the impact of rocks against the river bed is in the range 10-150 Hz. Furthermore, the high-frequency band of underground sounds decays much more rapidly than that of airborne sounds. The spatial decay rate of airborne sounds was also determined and compared with theoretical values. The lower spatial decay rate of airborne sounds than that of underground sounds suggests that monitoring of airborne sounds may be more efficient in the detection of debris flows or other natural hazards that generate both airborne and underground sounds.
\end{abstract}

\section{Introduction}

Ground vibrations, sometimes called underground sounds or geo-sounds, are typically caused by earthquakes, volcanic eruptions, debris flows, landslides and the impact of rocks on the ground. Most ground vibrations that result from debris flows are induced by the collision and friction of rocks with river bed (Huang et al., 2007). Ground vibrations are elastic waves that propagate into the Earth and along its surface. Previous studies have revealed in great detail the characteristics of ground vibrations caused by debris flows, and the vibration properties are summarized as follows (Okuda et

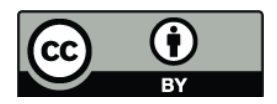

Correspondence to: C.-J. Huang

(cjhuang@mail.ncku.edu.tw) al., 1980; Itakura, 1997; Arattano, 2000; Berti et al., 2000; Huang et al., 2004 and 2007). 1. The frequency of vibrations ranges mainly between 10 and $300 \mathrm{~Hz}$. 2 . The peak frequency ranges from $10-30 \mathrm{~Hz}$ at the surge front to $60-80 \mathrm{~Hz}$ at the flow tail. 3. The amplitude of ground vibrations is proportional to the debris flow discharge. Accordingly, debris flows can be detected whenever the amplitude of the ground vibrations exceeds a threshold over a certain frequency range for a given period.

The Debris Flow Monitoring System established by the Soil and Water Conservation Bureau (SWCB) in Taiwan has detected several debris flows using geophones (Yin, 2005; Huang et al., 2007). However, ground tremors caused by debris flows are significantly smaller than ground vibrations caused by earthquakes, and have a higher-frequency range. Seismic wave attenuation depends on frequency. Therefore, a high frequency corresponds to a high decay rate (Toksöz and Johnston, 1981). As a result, debris flow tremors can only be detected within a relatively short distance. Although this shortcoming can be overcome by installing sensors close to the origin of debris flows, deploying long cables causes not only high signal attenuation, but also transmission uncertainty in mountainous regions.

Debris flows cause rocks or boulders to interact with the river bed, producing ground vibrations (underground sound) and loud noises (airborne sound). Monitoring airborne sound can also detect the occurrence of debris flows. In fact, many investigators have deployed microphones that are sensitive to infrasound to monitor volcano eruptions (Richard, 1963; Vergniolle et al., 1996; Hagerty et al., 2000; Johnson, 2003). Volcanic infrasound appears to be dominated by frequencies between $0.5 \mathrm{~Hz}$ and $10 \mathrm{~Hz}$. Researchers believe the rapid release of pressurized gas at the earth surface is the fundamental source of volcano infrasound (Johnson, 2003). Airborne sound tends to be less distorted than underground sound, because the atmosphere is largely devoid of obstacles that scatter, attenuate, or reflect acoustic waves. In some

Published by Copernicus Publications on behalf of the European Geosciences Union. 
Table 1. Atmospheric conditions for field tests at Hua-Shan Creek.

\begin{tabular}{cccc}
\hline Date & 16 Dec 2006 & 23 March 2007 & 16 May 2007 \\
\hline Weather & Rainy & Half cloudy & Half cloudy and windy \\
Temperature $\left({ }^{\circ}\right) \mathrm{C}$ & 13 & 26 & 31 \\
Humidity $(\%)$ & 100 & 80 & 93 \\
\hline
\end{tabular}

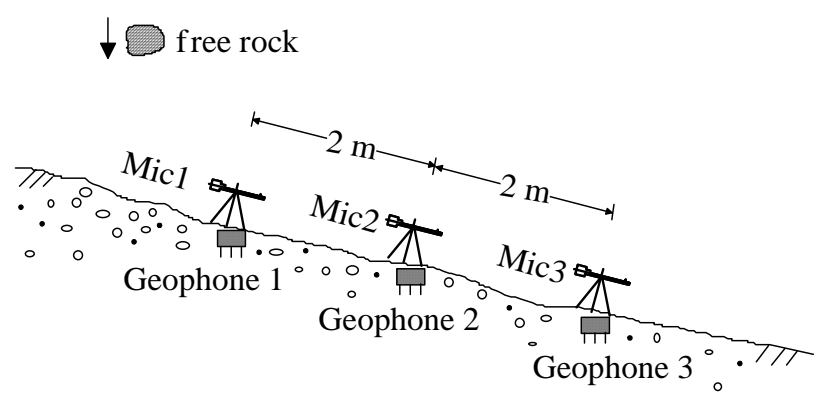

Fig. 1. Experimental setup for measuring both the underground and airborne sounds generated by a rock falling freely onto a river bed.

cases, however, wind turbulence and interface between the atmosphere and the ground may scatter and reflect the sound waves.

In this study, field tests were performed to compare the underground and airborne sounds that are produced by a rock in a river bed. The characteristics of both sounds are discussed in terms of frequency range, phase speed and spatial decay rate. Since the motion of rocks on the ground is the main source of ground vibrations or airborne sounds associated with debris flows, debris avalanches and landslides, the results of this study may be of great help in designing sensors for detecting these natural hazards.

\section{Signal processing and analysis}

Fast Fourier Transform (FFT) is often applied to transform time-series data into the frequency domain to reveal the spectral behaviors of periodic signals. However, ground vibrations or airborne sounds that are produced by natural hazards, such as debris flows or debris avalanches, are characterized by abrupt transitions, discontinuities, damping, and non-stationary features. In addition to the FFT, this work uses the Gabor transform (Gabor, 1946; Friedlander and Porat, 1989; Friedlander and Zeira, 1995) to represent the time series data of airborne sound in the time-frequency domain. Thus, not only the spectral properties but also the temporal evolutions of the signals are revealed. The Gabor representation of a time-series signal $y(t)$ using the window function $g(t)$ is

$y(t)=\sum_{m=-\infty}^{\infty} \sum_{n=-\infty}^{\infty} C_{m, n} g(t-n \Delta t) \exp (2 \pi i m \Delta f t)$
Table 2. Experimental conditions for field tests at Hua-Shan Creek.

\begin{tabular}{cccccc}
\hline No. Date & $\begin{array}{c}\text { Rock } \\
\text { weight } \\
(\mathrm{kg})\end{array}$ & $\begin{array}{c}\text { Distance } \\
\text { between } \\
\text { the } \\
\text { sensors } \\
(\mathrm{m})\end{array}$ & $\begin{array}{c}\text { Release } \\
\text { height } \\
(\mathrm{m})\end{array}$ & $\begin{array}{c}\text { Impact } \\
\text { distance } \\
\text { from } \\
\text { the } \\
\text { first } \\
\text { sensor } \\
(\mathrm{m})\end{array}$ \\
\hline 1 & $16 \mathrm{Dec}$, & 30 & 2 & 1.2 & 1 \\
2 & 2006 & 50 & 2 & 1.2 & 1 \\
3 & $23 \mathrm{Mar}$ & 25 & 2 & 1.2 & 1 \\
4 & 2007 & 50 & 2 & 1.2 & 1 \\
5 & $16 \mathrm{May}$ & $*(70 \times 70 \times 27)$ & 5 & 3.8 & 6.2 \\
6 & 2007 & $*(60 \times 50 \times 40)$ & 5 & 3.8 & 6.2 \\
\hline
\end{tabular}

${ }^{*}$ Rock size is specified in dimension $\left(\mathrm{cm}^{3}\right)$.

$$
=\sum_{m=-\infty}^{\infty} \sum_{n=-\infty}^{\infty} C_{m, n} g_{m, n}(t)
$$

where $C_{m, n}$ represents Gabor coefficients and $\Delta t$ and $\Delta f$ are the time and frequency sampling steps. The Gabor transform is intended to solve for $C_{m, n}$. The function $g(t-n \Delta t)$ is a one-sided exponential window function and is

$g(t)=\sqrt{2 \lambda / \Delta f} \exp (-\lambda t) u(t)$

where $u(t)$ is the unit step function. The parameter $\lambda$ is the damping coefficient, which is employed to control the effective window width. After the biorthogonal function of the window function $g_{m, n}(t)$ is solved, the biorthogonal function is substituted into Eq. (1) to determine $C_{m, n}$. Notably from Eq. (1), since $g_{m, n}(t)$ is dimensionless, the Gabor coefficient $C_{m, n}$ has the same physical meaning as $y(t)$. Previous studies (Huang et al., 2004) determined the $\lambda$ value of underground sounds produced by the motion of rocks to be $55 s^{-1}$, where $s$ denotes the time in seconds. Since the Gabor transform is insensitive to the damping coefficient, this value was used in the Gabor transform throughout this work.

\section{Experimental setups}

Figure 1 presents a typical experimental setup for detecting both underground and airborne sounds produced by the free falling rocks onto a river bed. A geophone (GS-20DX, Geospace Technologies, USA) installed in the river bed surface monitors ground vibrations. This geophone can detect vibrations in three perpendicular axes. Three geophones are installed in a straight line. The gap between two adjacent geophones is either $5 \mathrm{~m}$ or $2 \mathrm{~m}$, depending on the weight of the rock that hits the river bed. Similarly, three microphones (B\&K 4190) are positioned in the same locations as the geophones to monitor airborne sounds. The microphones are mounted about $80 \mathrm{~cm}$ above the ground. The GS-20DX geophones detect frequencies from 8 to $1500 \mathrm{~Hz}$, while the B\&K 
4190 microphones detect frequencies from $3 \mathrm{~Hz}$ to $20 \mathrm{kHz}$. Sponge blocks are mounted on the base of the frames that support the microphones to prevent any ground vibration interference due to the motion of rocks. Analogous signals from the geophones and microphones are converted into digital data for further signal processing. The experimental sampling rate is set to $500 \mathrm{~Hz}$ to resolve the vibration signals accurately.

Each test was repeated 2-3 times under identical conditions to yield reliable data. The physical quality detected by geophones was velocity $(\mathrm{cm} / \mathrm{s})$, while the microphones detected pressure $(\mathrm{Pa})$. Field tests were performed at Hua-Shan Creek at Yuen-Lin Hsien, Taiwan, where the bedrock consists of hard shale and colglomerate. The soil in this location consists of colluvium and stony soil. Field tests were conducted on three separate days under different weather conditions listed in Table 1. Table 2 specifies the rock weight, the release height and the distance between the sensors in each test. The rock weight and release height in the first four tests are much smaller than those in the tests Nos. 5 and 6; the ground vibrations thus obtained are smaller. Since the ground vibration decays rapidly, the distance between the sensors is set to $2 m$ so that the sensors that are farther away from the impact point can detect signals. In tests Nos. 5 and 6 , a large boulder was pushed to fall down onto the river bed from a check dam that was $3.8 \mathrm{~m}$ high. The ground vibration thus obtained was much larger; hence, the distance between the sensors was adjusted to $5 \mathrm{~m}$. Similarly, for the sake of safety, the impact distance from the first sensor was set to $6.2 \mathrm{~m}$. The reason for performing the last two tests is to check the effect of a large rock weight and release height on the frequency range of the ground vibrations and airborne sounds.

\section{Results and discussion}

Background noises were first measured to help identify ground vibrations and airborne sounds generated during these experiments. Measurements indicated that the background noise for ground vibrations is rather stable, with a small velocity amplitude of $0.004 \mathrm{~cm} / \mathrm{s}$ and a frequency of $10 \mathrm{~Hz}$. However, background noise seems to be a greater issue for airborne sounds because of wind sensitivity. Wind speed was not measured during the experiments. Figure 2 shows the typical background noise for airborne sounds that were detected in field tests performed on 16 May 2007, which was a windy day. Figure 2 a plots time-series data, Fig. $2 b$ plots signals in the frequency domain obtained using the Fast Fourier Transform (FFT) and Fig. 2c plots the Gabor coefficients of the time-domain signal. Signals in the frequency and time-frequency domains suggest that most frequencies are below $10 \mathrm{~Hz}$.

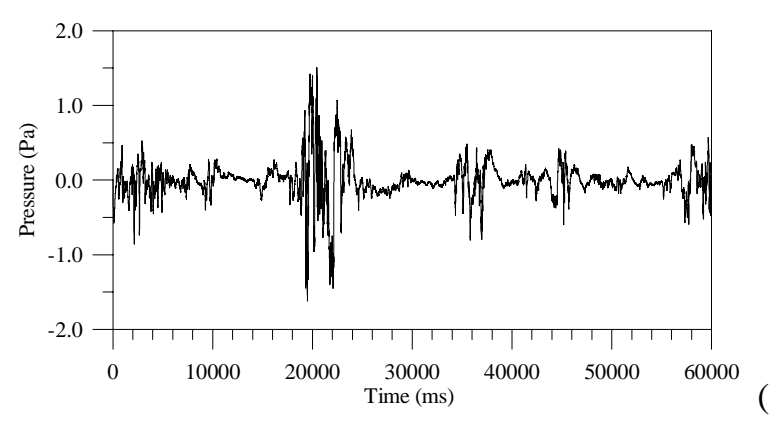

(a)

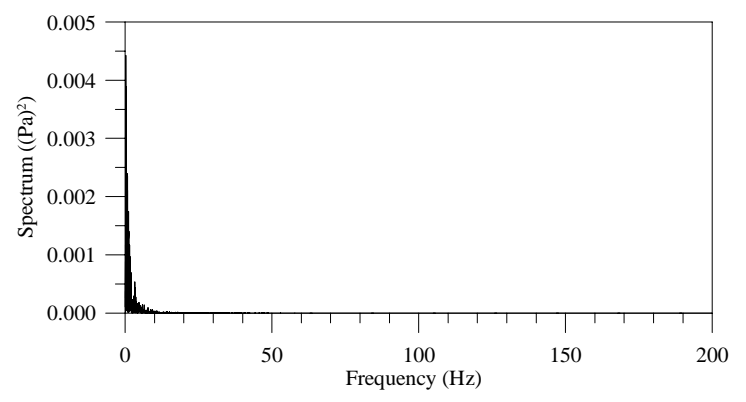

(b)

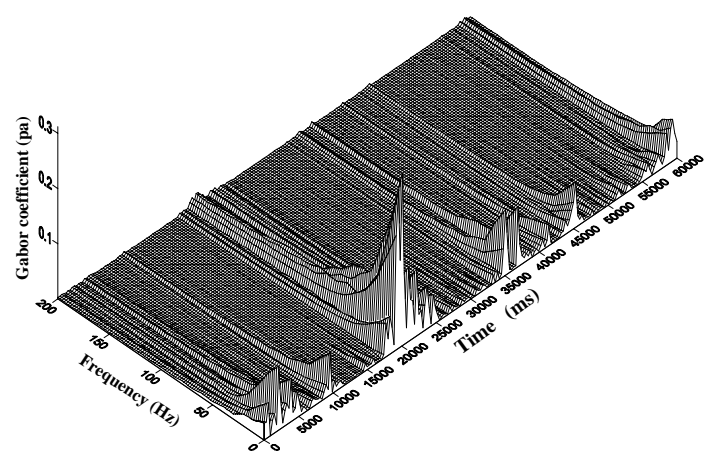

(c)

Fig. 2. Background noise in the air detected by the microphone during the field test performed at Hua-Shan Creek on 16 May 2007, a windy day; (a) time-domain signal, (b) signals in the frequency domain obtained using FFT, and (c) Gabor coefficients of the timedomain signal.

\subsection{Frequency range}

Figures 3 to 5 plot ground vibrations along the Y-axis that were detected by the geophones in experiment No. 1 (Table 2). Signal behaviors along the other two axes ( $X$ and $Z$ ) are very similar to that along the $\mathrm{Y}$-axis and are omitted. For relevant details, refer to Huang (2007). The X-axis is parallel to the channel bed, the Y-axis perpendicular to the channel, and the Z-axis is vertical. Figures 6 to 8 present the corresponding airborne sounds as detected by microphones. Figure 3 plots the frequency of ground vibration, which varies from 10 to $120 \mathrm{~Hz}$. Figures 3 to 5 reveal that the velocity 

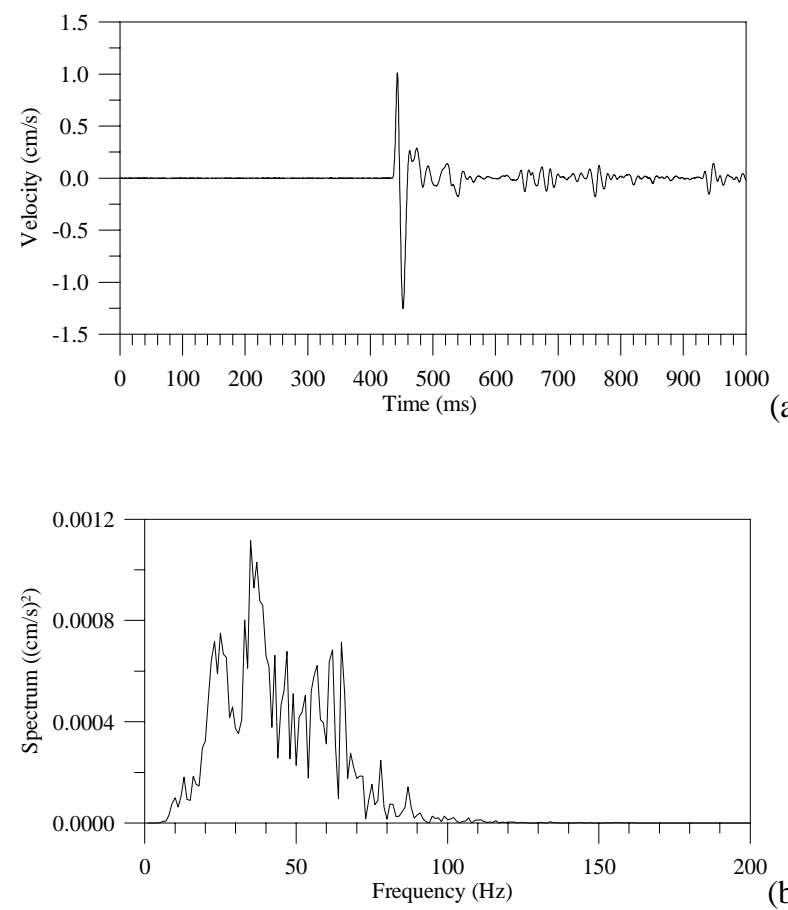

(b)

Fig. 3. Ground vibrations along the Y-axis for experiment No. 1 (Table 2) detected by the first geophone: (a) time-domain signal and (b) signals in the frequency domain obtained using FFT.

amplitude of the ground vibrations declines rapidly as the distance from the impact point increases. Similarly, the frequency range, especially the high-frequency band, decreases significantly as the distance increases. In fact, the third geophone could not detect signals with frequencies of higher than $50 \mathrm{~Hz}$.

The results in Fig. 2 indicate that airborne sounds with a frequency lower than $10 \mathrm{~Hz}$ are mostly background noise. Hence, to prevent the confusion of background noise with real airborne sounds produced by the motion of rocks, signals of frequencies of less than $10 \mathrm{~Hz}$ were filtered out in parts (b) of Figs. 6 to 8. However, the time-history characteristics of acoustic signals with frequencies less than $10 \mathrm{~Hz}$ can still be recognized from the Gabor coefficient in the timefrequency domain, Fig. 9c. The sound signals in Figs. 6 to 8 show that both the sound pressure and the frequency range of airborne sounds detected by the three microphones are approximately equal, indicating that airborne sounds decay only slightly. Comparing airborne sounds in Figs. 6 to 8 with underground sounds in Figs. 3 to 5 reveals that the frequency range of the airborne sounds is the same as that of the underground sounds that were detected by the first geophone $-10-120 \mathrm{~Hz}$. This similarity demonstrates both sounds emanated from the same seismic source.

Ground vibrations obtained under various experimental conditions of stone weight, release height and grain size
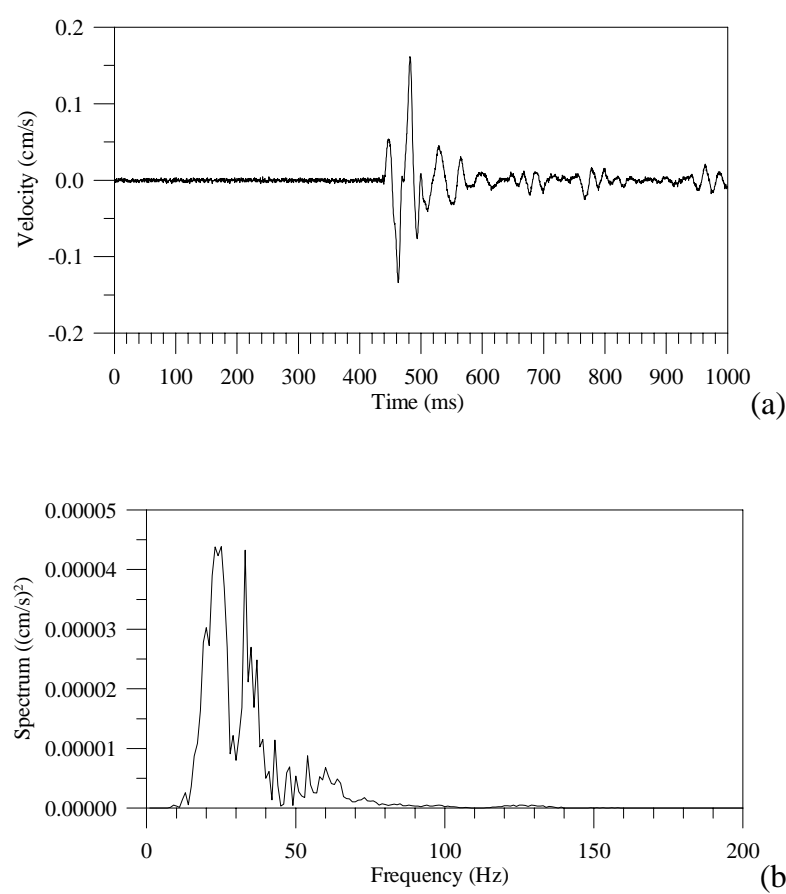

(b)

Fig. 4. Ground vibrations along the Y-axis for experiment No. 1 (Table 2) detected by the second geophone: (a) time-domain signal and (b) signals in the frequency domain obtained using FFT.

composition, behave more or less like those in Figs. 3 to 5 and have been thoroughly investigated by Huang et al. (2004 and 2007). The peak frequency of ground vibrations usually shifts to a lower value as the weight of the rock increases, perhaps because the impact of larger stones causes more earth material around the impact point to vibrate. If the vibration system is modeled as the typical mass-spring system, then the vibration frequency of the mass is inversely proportional to the square root of the mass.

This study also examines the effects of weather on the propagation of airborne sounds. Figure 9 presents airborne sounds that are detected by the first microphone and generated by the release of a large boulder with dimensions of $60 \times 50 \times 40 \mathrm{~cm}^{3}$ from a check dam and falling on a test site close to the previous one. The release height is $3.8 \mathrm{~m}$. Airborne sounds that are detected by the second and third microphones are similar to those displayed in Fig. 9 and are omitted. Since the rock is heavy, it rebounds after the primary impact and when it hits the bed again, it produces secondary ground vibrations, as shown in Fig. 9a. Figure 9c presents the Gabor coefficients of the time-domain signals, to provide more information on the temporal and spectral behaviors of the acoustic signals. As stated above, experiment No. 6 was performed on a windy day, so the acoustic background noise in Fig. 9 exceeded that in Figs. 6 to 8. The spectral behavior of the lower-frequency acoustic signals, presented in Fig. 9c, 


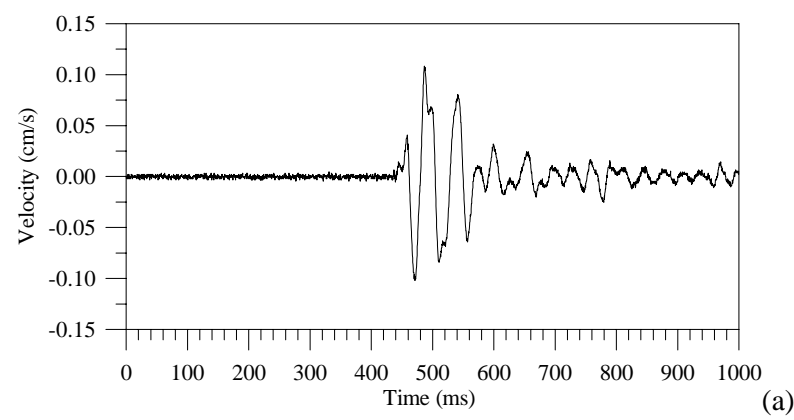

(a)

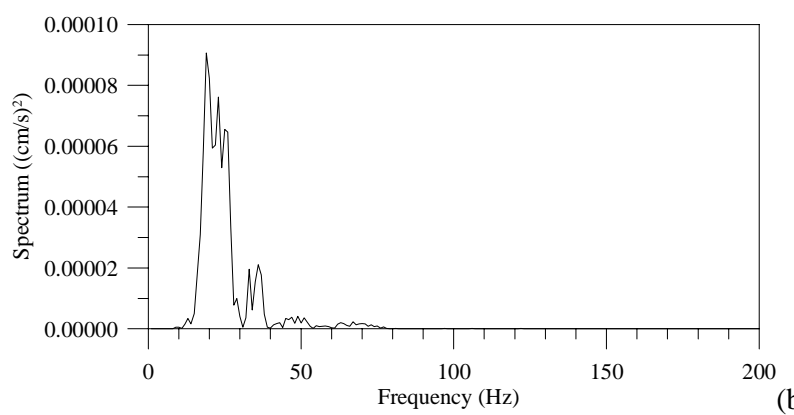

(b)

Fig. 5. Ground vibrations along the Y-axis for experiment No. 1 (Table 2) detected by the third geophone: (a) time-domain signal and (b) signals in the frequency domain obtained using FFT.

is consistent with that presented in Fig. 2. The frequency range of the sound pressure in Fig. 9 is wider than that in Figs. 6 to 8. The frequency in Fig. 9 extends to $200 \mathrm{~Hz}$. The additional sound signals may have been generated because the rock used in experiment No. 6 is much larger and heavier than that adopted in experiment No. 1, such that the amplitude of the higher-frequency sounds is also much greater. Even at a greater distance from the seismic source $(6.2 \mathrm{~m})$, they can still be detected.

\subsection{Phase speed}

The impact of a rock on a river bed produces ground vibrations, which can be interpreted as elastic waves. The parts of elastic waves that propagate into the earth are called body waves, and those that propagate along the surface of the earth are called surface waves, or Rayleigh waves. Ground vibrations that are detected by geophones installed on the earth surface resemble Rayleigh waves. Researchers are still developing theories for evaluating the phase speed of Rayleigh waves in porous or granular media (Tajuddin, 1984; Wang and Zhang, 1998). For practical purposes, this phase speed is often assumed to be the same as that of shear waves. Huang et al. (2007) and Chen et al. (2007) used the spherepacking model of granular rocks that was proposed by Duffy and Mindlin (1957) to estimate the theoretical phase speed

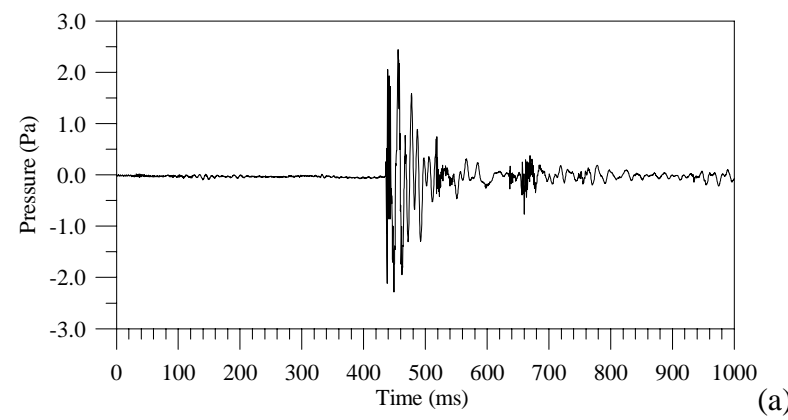

(a)

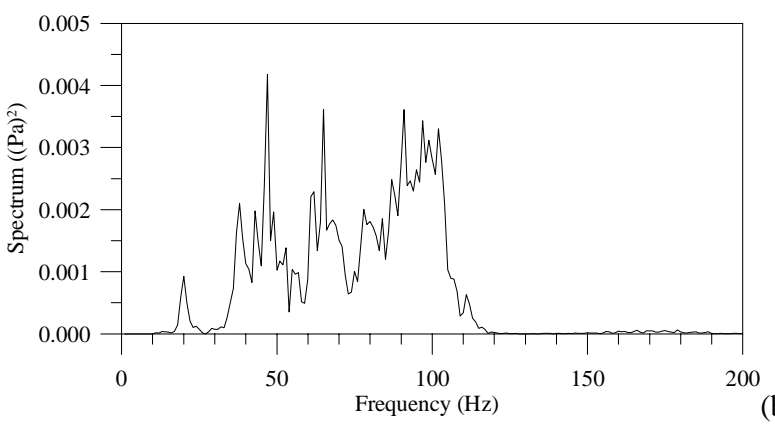

(b)

Fig. 6. Airborne sounds for experiment No. 1 (Table 2) detected by the first microphone: (a) time-domain signal and (b) signals in the frequency domain obtained using FFT.

of ground vibrations for comparison with the experimental data. The estimated phase speed of ground vibrations in unsaturated porous material is $241 \mathrm{~m} / \mathrm{s}$ if the porous material is assumed to be quartz sand with $\rho_{s}=2.65 \times 10^{3} \mathrm{~kg} / \mathrm{m}^{3}$, $v_{s}=0.15, E_{s}=10^{11} \mathrm{~N} / \mathrm{m}^{2}$ and $k_{s}=35 \times 10^{9} \mathrm{~N} / \mathrm{m}^{2}$ (Schön, 1996). Here, $\rho_{s}$ denotes the density, $v_{s}$ is the Poisson ratio, and $E_{s}$ is the elastic modulus of the solid of which the spheres are made.

The experimental phase speed of ground vibrations was determined as follows. The time-domain signal on the Yaxis was recorded using three geophones. Each sensor detected the signal's arrival time. The propagation speed was then calculated by dividing the distance between adjacent geophones by the time required for the ground vibration to move from one geophone to the next. For the ground vibrations displayed in Figs. 3 to 5, the signal arrival times at the three geophones are $436 \mathrm{~ms}, 438.5 \mathrm{~ms}$ and $441 \mathrm{~ms}$, respectively. The propagation speed of the ground vibrations between the first and second geophone, $V_{12}$, is then $2 \mathrm{~m} /(438.5-436) \mathrm{ms}=800 \mathrm{~m} / \mathrm{s}$. That between the second and the third geophone, $V_{23}$, equals $V_{12}$. This value substantially exceeds the theoretical value, $241 \mathrm{~m} / \mathrm{s}$. Huang et al. (2007) noted that the propagation speed of ground vibrations through fine-grained soil with a smaller concentration of coarse sediment is closer to the theoretical value. Table 3 

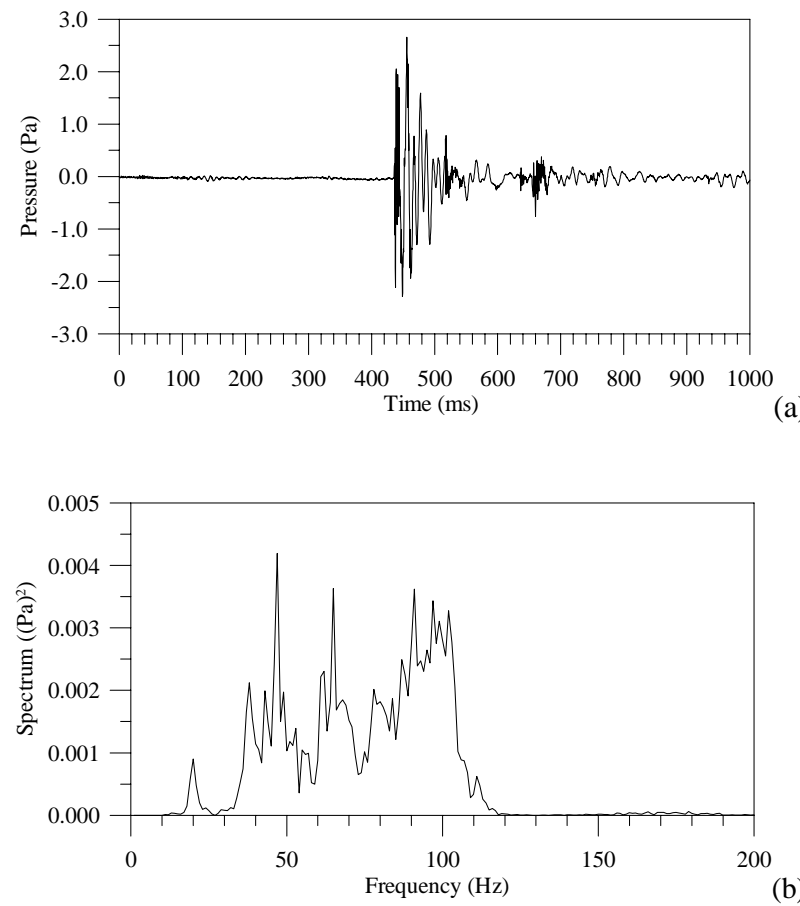

Fig. 7. Airborne sounds for experiment No. 1 (Table 2) detected by the second microphone: (a) time-domain signal and (b) signals in the frequency domain obtained using FFT.

lists the frequency range and phase speed of ground vibrations obtained under various experimental conditions.

The propagation speed of ground vibrations depends very much on the earth material and is difficult to determine. In contrast, the speed of sound in the air is well known. It depends mainly on the air temperature and can easily be determined as

$c_{\text {air }}=331.45+0.16 T$ (in Celsius), $(\mathrm{m} / \mathrm{s})$

The phase speed of airborne sounds can also be determined from sound signals that are recorded by the microphones following the same procedure as used for ground vibrations. However, identifying the exact arrival time of the signal becomes difficult as the background noise increases. An alternative approach is to identify the time of the peak sound pressure for different microphones. The peak sound pressure in Fig. 9a and other corresponding figures appears at $2510 \mathrm{~ms}, 2524 \mathrm{~ms}$ and $2538 \mathrm{~ms}$ for the first to third microphone, respectively. The sound speed is then calculated as $5 \mathrm{~m} / 14 \mathrm{~ms}=357.14 \mathrm{~m} / \mathrm{s}$. According to Eq. (3) the theoretical value is $336.41 \mathrm{~m} / \mathrm{s}\left(T=31^{\circ} \mathrm{C}\right)$. The experimental data provide a reasonable value for the sound speed. Increasing the sampling rate will improve the accuracy of the experimental value. This study uses a sampling rate of $500 \mathrm{~Hz}$, implying that the time interval is $2 \mathrm{~ms}$. This sampling rate is too low to determine accurately the time in "milliseconds". Nevertheless, this example demonstrates the reliability of the

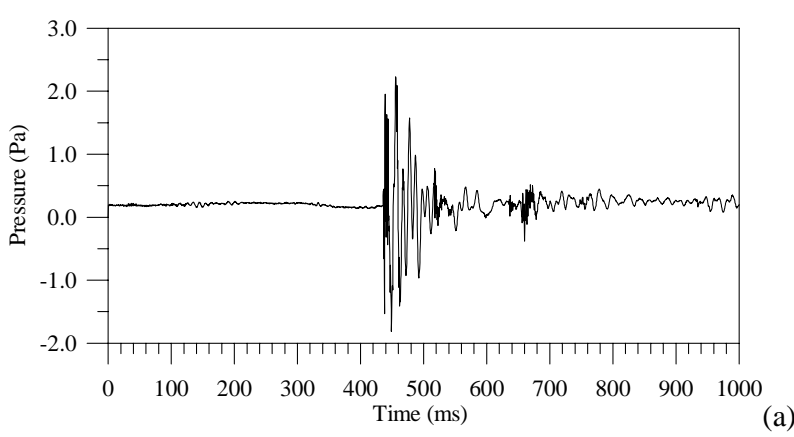

(a)

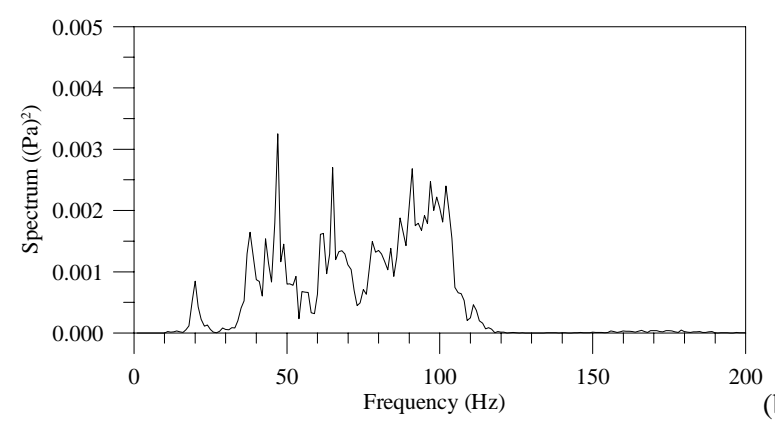

(b)

Fig. 8. Airborne sounds for experiment No. 1 (Table 2) detected by the third microphone: (a) time-domain signal and (b) signals in the frequency domain obtained using FFT.

approach that is used to determine the phase speed of ground vibrations and airborne sounds.

\subsection{Decay rate}

Both ground vibrations and airborne sounds are subject to attenuation as they propagate in their respective media - the former in earth and the latter in air. Ground vibrations that propagate along the earth surface resemble cylindrical waves. Accordingly, the velocity amplitude of ground vibrations can be expressed as

$V(r)=\frac{\tilde{A}}{\sqrt{r}} e^{-\alpha r}$

where $r$ is the distance from the seismic source; $\alpha$ is the attenuation coefficient or the decay rate with dimension $L^{-1}$; $L$ is the length, and $\tilde{A}$ denotes the product of initial amplitude and a phase function that specifies the propagation of waves, such as $e^{i k(r-c t)}$, where $k$ is the wave number, $c$ is the propagation speed of the waves and $t$ is the time. In Eq. (4) the farfield asymptotic behavior of the zeroth-order Hankel function has been applied. The amplitude given by Eq. (4) decays in two ways because it is proportional to $1 / \sqrt{r}$ and $e^{-\alpha r}$. The first decay is caused by the geometrical effect of energy distribution, and is called "geometrical spreading." This decay does not cause energy loss. Ground vibration propagation in 

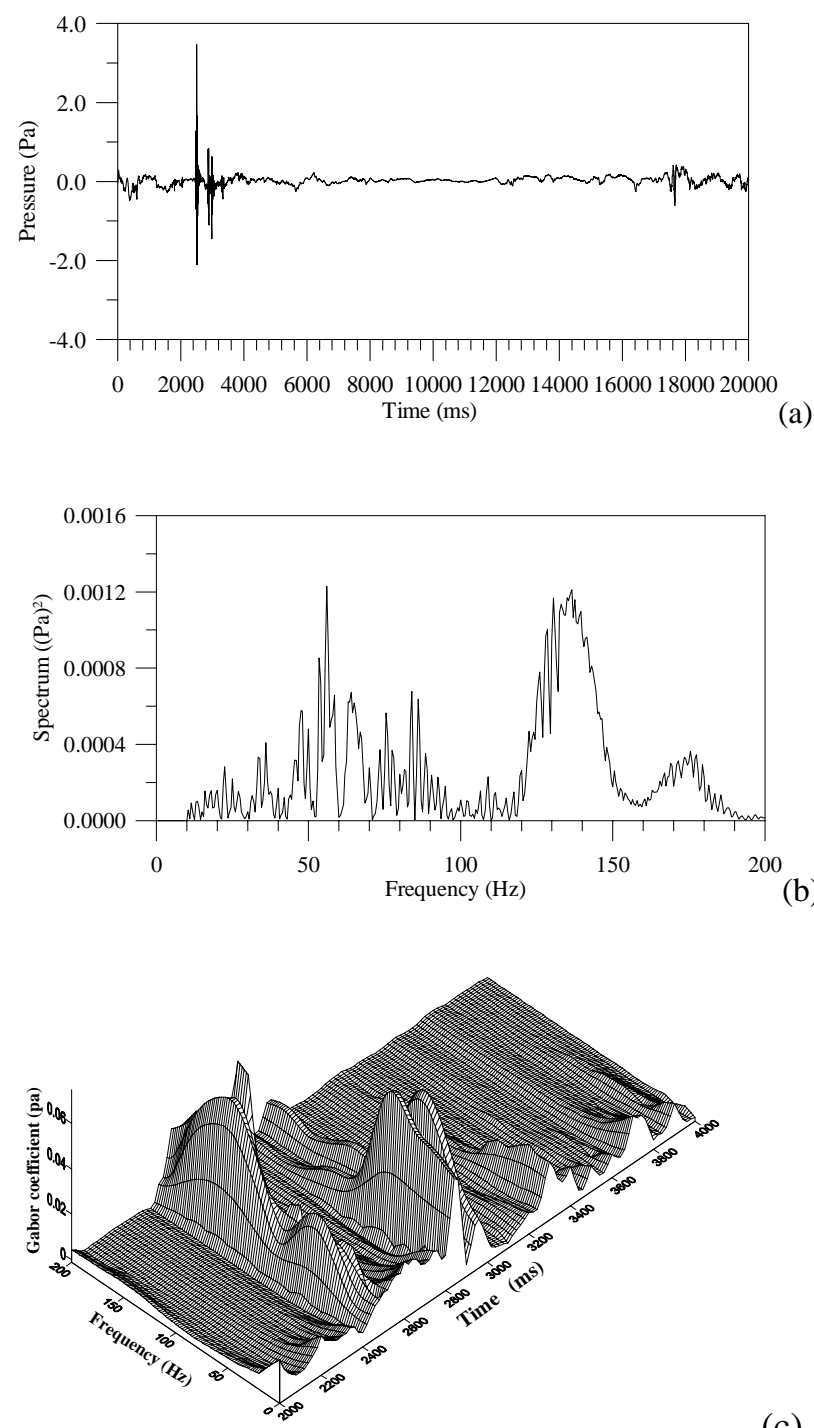

(c)

Fig. 9. Airborne sounds for experiment No. 6 (Table 2) detected by the first microphone: (a) time-domain signal, (b) signals in the frequency domain obtained using FFT, and (c) Gabor coefficients of the time domain signal.

the medium due to friction causes the second decay and is addressed herein. Equation (4) can be rewritten as

$V(r)=\frac{A}{\sqrt{r}} e^{-\alpha\left(r-r_{1}\right)}$

where $r_{1}$ is the distance from the first geophone to the seismic source. The velocity amplitude measured by the first geophone is assumed to be $V_{1}$; substituting this value into Eq. (5) yields

$\frac{V(r)}{V_{1}}=\frac{1}{\sqrt{r / r_{1}}} e^{-\alpha r_{1}\left(r / r_{1}-1\right)}$
Table 3. Underground sounds produced by rocks hitting the river bed.

\begin{tabular}{cccrrrr}
\hline $\begin{array}{c}\text { Experiment } \\
\text { No. }\end{array}$ & $\begin{array}{c}\text { Frequency } \\
\text { range } \\
(\mathrm{Hz})\end{array}$ & $\begin{array}{c}\text { Peak } \\
\text { frequency } \\
(\mathrm{Hz})\end{array}$ & $\begin{array}{c}\text { Phase speed } \\
(\mathrm{m} / \mathrm{s})\end{array}$ & \multicolumn{2}{c}{$\begin{array}{c}\text { Experimental } \\
\text { decay rate } \\
\left(\mathrm{m}^{-1}\right)\end{array}$} \\
& & & $V_{12}$ & $V_{23}$ & $\alpha_{12}$ & $\alpha_{13}$ \\
\hline 1 & $10 \sim 130$ & 35 & 800 & 800 & 1.3437 & 0.4264 \\
2 & $10 \sim 100$ & 25 & 666.7 & 666.7 & 1.5304 & 0.3694 \\
3 & $10 \sim 150$ & 35 & 500 & 1000 & 0.6581 & 0.7458 \\
4 & $10 \sim 120$ & 35 & 666.7 & 1000 & 0.7292 & 0.5623 \\
5 & $10 \sim 150$ & 35 & 166.67 & 277.78 & 0.2808 & 0.2266 \\
6 & $10 \sim 100$ & 30,40 & 357.14 & 357.14 & 0.3007 & 0.2054 \\
\hline
\end{tabular}

The spatial decay rate can be determined using Eq. (6), given the position of the second or third geophone and the measured velocity amplitude. Table 3 presents the decay rates for ground vibrations under different experimental conditions, where $\alpha_{12}$ is the decay rate between the first and second geophones, and $\alpha_{13}$ is the decay rate between the first and third geophones. The decay rates should be about the same in all of the test cases that are presented in Table 3 because the geophones are in fixed locations. The variation of the decay rates may follow from the following causes: (1) the geological heterogeneity of the river bed between geophones; (2) the dependence of the attenuation of elastic waves on frequency, along with the fact that no test can produce ground vibrations of exactly equal frequencies, and, (3) the inappropriateness of the model for determining decay rate.

Sound propagates in the atmosphere in the form of spherical waves. Like ground vibrations, the spatial decay rate of airborne sounds caused by the motion of rocks can be calculated from the following equation;

$\frac{p(r)}{p_{1}}=\frac{1}{r / r_{1}} e^{-\alpha r_{1}\left(r / r_{1}-1\right)}$

where $p_{1}$ denotes the amplitude of the sound pressure that is detected by the first microphone. Sound wave decay in the atmosphere was determined in detail based on the assumption that sound waves are plane waves (Blackstock, 2000). The expression obtained for $\alpha$ also holds for sounds that propagate in other forms, such as spherical waves. Sound can be absorbed by viscosity, heat conduction, relaxation and other loss mechanisms, such as wind turbulence. The sum of relaxation absorption is associated with the vibration of nitrogen and oxygen molecules. Total absorption changes markedly with relative humidity, because the relaxation frequencies of nitrogen and oxygen depend largely on the amount of water vapor in the air.

The spatial decay rate $\alpha$ of airborne sound can be determined as follows (Blackstock, 2000)

$\alpha=\frac{B_{1} f_{r, N} f^{2}}{f^{2}+f_{r, N}^{2}}+\frac{B_{2} f_{r, o} f^{2}}{f^{2}+f_{r, o}^{2}}+B_{3} \frac{p_{s}}{p_{s o}} f^{2}$ 
Table 4. Airborne sounds generated by rocks hitting the river bed.

\begin{tabular}{cccrrr}
\hline $\begin{array}{c}\text { Experiment } \\
\text { No. }\end{array}$ & $\begin{array}{c}\text { Frequency } \\
\text { range } \\
(\mathrm{Hz})\end{array}$ & $\begin{array}{c}\text { Peak } \\
\text { frequency } \\
(\mathrm{Hz})\end{array}$ & $\begin{array}{r}\text { Theoretical } \\
\text { decay rate } \\
\left(\mathrm{m}^{-1}\right)\end{array}$ & $\begin{array}{r}\text { Experimental } \\
\text { decay rate } \\
\left(\mathrm{m}^{-1}\right)\end{array}$ \\
\hline 1 & $10 \sim 110$ & 45 & $4.682 \mathrm{E}-6$ & -0.507 & -0.358 \\
2 & $10 \sim 100$ & 40 & $3.707 \mathrm{E}-6$ & -0.525 & -0.346 \\
3 & $10 \sim 150$ & 35 & $2.288 \mathrm{E}-6$ & 0.007 & -0.061 \\
4 & $10 \sim 200$ & 35 & $2.288 \mathrm{E}-6$ & -0.302 & -0.149 \\
5 & $10 \sim 150$ & 35 & $2.233 \mathrm{E}-6$ & -0.047 & -0.034 \\
6 & $10 \sim 200$ & 60 & $4.927 \mathrm{E}-6$ & -0.054 & -0.014 \\
& & 140 & $2.648 \mathrm{E}-6$ & & \\
\hline
\end{tabular}

where $f$ is the frequency in Hertz; $f_{r, N}$ and $f_{r, O}$ are relaxation frequencies of nitrogen and oxygen, respectively; $p_{s}$ is the local atmospheric pressure; $p_{s o}$ is the reference atmospheric pressure (1 atm), and $B_{1}, B_{2}$ and $B_{3}$ are functions of temperature. Blackstock (2000) has presented formulas for determining $f_{r, N}, f_{r, O}, B_{1}, B_{2}$ and $B_{3}$.

Table 4 presents the theoretical and experimental decay rates of airborne sounds that are generated by the impact of a rock on a river bed. The peak frequency serves as the reference frequency for determining the theoretical decay rates, and $p_{s}$ is assumed to be $1 \mathrm{~atm}$. The peak pressures detected at different microphones were examined using Eq. (6) to obtain experimental decay rates. Notably, the theoretical decay rates of low-frequency sounds are very low, indicating that a drop in sound pressure in the atmosphere is caused mostly by geometrical spreading. Theoretically speaking, the experimental decay rates should approach the theoretical values and thus come very close to zero. However, the measured sound pressures exceed the expected values, so most of the values of $\alpha$ are negative. The value of $\alpha$ deviates only slightly from zero except when the data were obtained on a rainy day (experiments No. 1 and No. 2). The following factors may be responsible for this deviation: (1) wind turbulence; (2) the fact that the microphones are mounted about $80 \mathrm{~cm}$ above the ground, and the rugged river bed may scatter and reflect sound waves, effectively changing the sound pressure near the microphone; and (3) experimental error. Regarding the smaller attenuation measured on the rainy day, more studies should be carried out to investigate the effect of rain on sound propagation in the atmosphere.

Comparing the decay rates in Tables 3 and 4 reveals that the decay rate of airborne sounds is much smaller than that of ground vibrations. This may indicate that airborne sounds produced by debris flows can be detected from a relatively greater distance. Debris flows in Taiwan usually occur during the typhoon season, when the weather is mostly rainy and very windy. Based on observations over the past four years (Huang, 2004, 2005, 2006, and 2007), weather and induced floods do not produce significant background noise in ground vibrations. However, this work demonstrates that weather can certainly cause significant pressure fluctuation in airborne sounds. Airborne sounds that result from wind and rain should be measured and analyzed to distinguish those that are produced by debris flows.

\section{Conclusions}

Field tests were carried out to investigate the difference between ground vibrations and airborne sounds that were produced by rock movements in a river bed. The ground vibrations and airborne sounds were detected by three geophones and microphones at three locations. Time series data were transformed into the frequency and time-frequency domains to elucidate their temporal and spectral characteristics. Based on the field test data, we conclude the following.

1. The velocity amplitude of ground vibrations decreases rapidly as the distance from the impact point increases. Similarly, the frequency range, especially the high-frequency band, decreases significantly as the distance increases. In fact, a geophone that is installed at a significant distance from the impact point cannot detect signals with frequencies of higher than $50 \mathrm{~Hz}$.

2. The frequency range of airborne sounds is the same as that of ground vibrations that are detected by a geophone installed close to the impact point, indicating that both the measured ground vibrations and the airborne sounds emanate from the same seismic source.

3. The decay rates of ground vibrations are analyzed by assuming that the ground vibrations propagate in cylindrical waves with an exponential attenuation. Similarly, the decay rates of airborne sounds are analyzed by assuming that the airborne sounds propagate in spherical waves.

4. The experimental decay rate of airborne sounds deviates only slightly from the theoretical decay rate, except when the data were obtained on a rainy day.

5. The spatial decay rate of airborne sounds is much smaller than that of ground vibrations.

Acknowledgements. The authors would like to thank the Soil and Water Conservation Bureau of the Council of Agriculture, Taiwan, for financially supporting this research under Contract No. SWCB-96-080. The authors are grateful to the Editor, M. Arattano and the anonymous reviewer for their helpful comments and suggestions.

Edited by: F. Guzzetti

Reviewed by: M. Arattano and another anonymous referee 


\section{References}

Arattano, M.: On debris flow front evolution along a torrent, Phys. Chem. Earth (B), 25(9), 733-740, 2000.

Berti, M., Genevois, R., LaHusen, R., Simoni, A., and Tecca, P. R.: Debris flow monitoring in the Acquabona Watershed on the Dolomites (Italian Alps), Phys. Chem. Earth (B), 25(9), 707715, 2000.

Blackstock, D. T.: Fundamentals of physical acoustics, John Wiley \& Sons, Inc., New York, 541 pp., 2000.

Chen, C. Y., Huang, C. J., and Yin, H. Y.: Propagation characteristics of ground vibrations produced by rock motions, the 4th Int. Conf. on Debris-Flow Hazards Mitigation: Mechanics, Prediction, and Assessment, Chengdu, China, in press, 10-13 September 2007.

Duffy, J. and Mindlin, R. D.: Stress-strain relations and vibrations of a granular medium, J. Appl. Mech., 24, 585-593, 1957.

Friedlander, B. and Porat, B.: Detection of transient signals by the Gabor representation, IEEE Trans. Acoust., Speech, Signal Process., 37(2), 169-180, 1989.

Friedlander, B. and Zeira, A.: Over-sampled Gabor representation for transient signals, IEEE Trans. Acoust., Speech, Signal Process., 43(9), 2088-2094, 1995.

Gabor, D.: Theory of communication, J. Inst. Electr. Eng., 93, 429459, 1946.

Hagerty, M., Schwartz, S. Y., Garces, M., and Protti, M.: Analysis of seismic and acoustic observations at Arenal Volcano, Costa Rica, 1995-1997, J. Volcano. Geotherm. Res., 101, 27-65, 2000.

Huang, C. J., Shieh, C. L., and Yin, H. Y.: Laboratory study of the underground sound generated by debris flows, J. Geophys. Res., 109, F01008, doi:10.1029/2003JF000048, 2004.

Huang, C. J.: Monitoring the ground vibrations of debris flows using geophones (I), Technical Report, SWCB-93-130, The Soil and Water Conservation Bureau, Council of Agriculture, 311 pp., Taiwan, 2004 (in Chinese).

Huang, C. J.: Monitoring the ground vibrations of debris flows using geophones (II), Technical Report, SWCB-94-104, The Soil and Water Conservation Bureau, Council of Agriculture, 288 pp., Taiwan, 2005 (in Chinese).

Huang, C. J.: Monitoring the ground vibrations of debris flows using geophones (III), Technical Report, SWCB-95-094, The Soil and Water Conservation Bureau, Council of Agriculture, 244 pp., Taiwan, 2006 (in Chinese).
Huang, C. J.: Monitoring the ground vibrations of debris flows using geophones (IV), Tech. Rep. SWCB-96-080, Soil and Water Conserv. Bur., Counc. of Agric., 143 pp., Taiwan, 2007 (in Chinese).

Huang, C. J., Yin, H. Y., Chen, C. Y., Yeh, C. H., and Wang, C. L.: Ground vibrations produced by rock motions and debris flows, J. Geophys. Res., 112, F02014, doi:10.1029/2005JF000437, 2007.

Itakura, Y., Koga, Y., Takahama, J. I., and Nowa, Y.: Acoustic detection sensor for debris flow, in Debris-Flow Hazards Mitigation: Mechanics, Prediction, and Assessment: Proc. of First Int. Conf., 747-756, Am. Soc. Civ. Eng., New York, 1997.

Johnson, J. B.: Generation and propagation of infrasonic airwaves from volcanic explosions, J. Volcano. Geotherm. Res., 121, 114, 2003.

Okuda, S., Okunishi, K., and Suwa, H.: Observation of debris flow at Kamikamihori Valley of Mt. Yakedade, in Excursion Guidebook of the 3rd Meeting of IGU commission on Field Experiment in Geomorphology, 127-130, Disaster Prev. Res. Inst. Kyoto Univ., Japan, 1980.

Richards, A. F.: Volcanic sounds: Investigation and analysis, J. Geophys. Res., 68, 919-928, 1963.

Schön, J. H.: Physical properties of rocks, Elsevier, Amsterdam, 583 pp., 1996.

Vergniolle, S., Brandeis, G., and Mareshal, J. C.: Strombolian explosions: 2. Eruption dynamics determined from acoustic measurements, J. Geophys. Res., 101, 20 449-20 466, 1996.

Tajuddin, M.: Rayleigh waves in a poroelastic half-space, J. Acoust. Soc. Am., 75 (3), 682-684, 1984.

Toksöz, M. N. and Johnston, D. H.: Seismic wave attenuation, Soc. Explor. Geophys., Geophysics Reprint Ser. 2, 459 pp., Tulsa, Okla, 1981.

Wang, Y. S. and Zhang, Z. M.: Propagation of Love waves in a transversely isotropic fluid-saturated porous layered half-surface, J. Acoust. Soc. Am., 103(2), 695-701, 1998.

Yin, H. Y.: Studying and monitoring the ground vibration generated by debris flows, PhD thesis, Department of Hydraulic and Ocean Engineering, National Cheng Kung University, Taiwan, 275 pp., 2005. 